\title{
PEMANFAATAN POLIMER HYBRID TMSPMA DAN PHOSPHOR ORGANIK SEBAGAI BAHAN LUMINESENSI UNTUK SOLID STATE LIGHTING PLANAR
}

\section{(APPLICATION OF HYBRID POLYMER OF TMSPMA AND ORGANIC PHOSPHOR AS LUMINESENCE MATERIAL FOR PLANAR SOLID STATE LIGHTING)}

\author{
Fitrilawati, Norman Syakir, Agustin P. Mastiti, Utami Yuliani, dan Annisa Aprilia \\ Laboratorium Material Maju, Program Studi Fisika, Fakultas MIPA Universitas Padjadjaran \\ JI. Raya Jatinangor KM 21, Kabupaten Sumedang \\ E-mail : fitrilawati@phys.unpad.ac.id
}

Received : 7 Oktober 2015; revised : 23 Oktober 2015; accepted : 27 Oktober 2015

\begin{abstract}
ABSTRAK
Lampu Solid State Lighting (SSL) planar, diharapkan dapat menghasilkan distribusi cahaya yang lebih baik, dibandingkan dengan lampu fluoresensi biasa. Berbeda dengan lampu SSL biasa, pada SSL panel lebar (planar) digunakan pendekatan kopling cahaya (Light Wave Coupling-LWC) sehingga memerlukan sistem light guiding, yaitu cahaya pengeksitasi dikopling ke dalam substrat sebagai media pandu gelombang. Untuk aplikasi lampu SSL planar dengan pendekatan LWC diperlukan lapisan pengkonversi warna emisi yang berukuran lebar dengan karakteristik yang sesuai dengan perangkat preparasi dan media pandu gelombang. Media pandu gelombang yang akan digunakan adalah Light Guide Plate (LGP), dari PMMA (polymethyl methacrylate). Pada penelitian ini dikembangkan bahan luminesensi berbasis polimer hybrid trimethoxysilylpropyl methacrylate (TMSPMA), yang dimodifikasi dengan teknik kopolimerisasi dan phosphor organik. Khusus pada bahan prekursor poli(TMSPMA) dilakukan uji kelarutan yang menunjukkan bahan prekursor polimer hybrid poli(TMSPMA) beserta kromofor organiknya dapat larut dengan baik pada pelarut polar. Dari hasil tersebut dipilih pelarut yang tepat sehingga pembuatan lapisan tipis dari bahan luminesensi organik dapat dilakukan secara sederhana dengan teknik screen printing. Lapisan tipis yang dihasilkan dengan teknik tersebut dapat mengemisikan cahaya ke seluruh permukaan secara merata sehingga memiliki potensi untuk pengembangan model lampu SSL planar.
\end{abstract}

Kata kunci : Polimer hybrid, Solid State Lighting, Poli(TMSPMA), Light Wave Coupling (LWC)

\begin{abstract}
Planar Solid State Lighting (SSL) expectedly giving a better lighting compared to ordinary fluorescent lamps. In comparasion to common SSL, in a wide panel (planar) SSL it is used a light coupling approach (Light Wave Coupling- $L W C$ ), so the system requires a guiding light and the excitation light integrated in substrate coupled to a wave guide media. Therefore a wide panel SSL using LWC approach required emission color converter layer which has suitable characteristics with a preparation equipments and wave guides medium. Light Guide Plate (LGP) will be used as a wave guide medium is PMMA (polymethyl methacrylate). This study will develop a hybrid polymer based luminescence materials trimethoxysilylpropyl methacrylate (TMSPMA) modified with copolymerization technique and organic phosphor. We conducted solubility test on a pure poly(TMSPMA) precursor and found that the precursor along with organic chromophores can dissolve well in polar solvents. By using the appropriate solvent we can prepare thin layers of the luminesence material using simple screen printing technique. The prepared screen printing film emitted light relatively uniform and show a prospect as wide panel SSL model.
\end{abstract}

Keywords : Hybrid polymer, Solid State Lighting, Poly(TMSPMA), Light Wave Coupling (LWC)

\section{PENDAHULUAN}

Perkembangan cukup signifikan telah berlangsung pada teknologi lampu, baik yang diaplikasikan pada perangkat elektronik hingga mainan anak-anak. Salah satunya adalah lampu 
berbahan dasar semikonduktor, SSL (Solid State Lighting) yang dikenal dengan nama lampu $L E D$ (Light Emitting Diode). Lampu SSL (LED) merupakan solusi untuk mengatasi kekurangan lampu Tube Lamp (TL) dan Cathode Fluorescence Lamp (CFL) (Crawford et al. 2013). Pada dasarnya lampu $T L$ dan CFL telah dinyatakan lebih hemat apabila dibandingkan dengan lampu pijar, namun masih terdapat kekurangan yaitu tidak ramah pada lingkungan dan kesehatan dikarenakan memiliki emisi berupa polutan gas merkuri dan sinar Ultraviolet (UV) (Zukaukas et al. 2002; Held 2009). Penemuan SSL/LED dirasakan dapat menyiasati kekurangan teknologi lampu sebelumnya. Selain itu, penggunaan $L E D$ dirasakan lebih efisien karena membutuhkan daya relatif lebih rendah dan ketahanan lebih lama dibandingkan dengan lampu CFL dan $T L$. Walaupun demikian, lampu LED masih memiliki beberapa kekurangan diantaranya adalah harga lebih mahal akibat biaya produksi cukup besar.

Dalam penelitian sebelumnya telah dilakukan studi penggunaan bahan phosphor organik dengan medium pendispersi berupa polimer hybrid sebagai bahan konversi panjang gelombang untuk prototipe lampu SSL (Fitrilawati dkk 2011). Pengembangan aplikasi lampu SSL dapat menggunakan dua pendekatan yaitu pendekatan eksitasi langsung (Direct Path Excitation-DPE) dan pendekatan kopling cahaya (Light Wave Coupling-LWC) (Tsao 2004; Steckl et al. 2005). Untuk mendapatkan prototipe lampu SSL berbentuk planar dapat dilakukan dengan pendekatan $L W C$, sehingga diperlukan lapisan pengkonversi panjang gelombang yang berukuran lebar beserta karakteristik yang sesuai dengan perangkat preparasi dan media pandu gelombang. Media pandu gelombang dapat berupa Light Guide Plate (LGP) yang umumnya terbuat dari PMMA (polymethyl methacrylate) (Travis et al. 2009; Travis et al. 2011). Lampu SSL planar diharapkan dapat menghasilkan distribusi pencahayaan dalam ruang yang lebih baik dibandingkan dengan lampu fluorescent biasa.

Pada makalah ini akan dikaji pembuatan lapisan tipis bahan pengkonversi warna (emisi) yang terbuat dari polimer hybrid trimethoxysilylpropyl methacrylate (TMSPMA), yang dimodifikasi dengan phosphor organik. Lapisan tipis tersebut dipreparasi dengan menggunakan teknik screen printing, setelah sebelumnya dilakukan uji kelarutan dengan beberapa jenis pelarut. Uji kelarutan dari bahan luminesensi yang dikembangkan ini merupakan taHAp untuk merealisasikan lampu SSL panel lebar dengan pendekatan $\angle W C$ dengan menggunakan media pandu gelombang LGP yang umumnya terbuat dari resin akrilik. Lapisan tipis tersebut kemudian diharapkan dapat diaplikasikan sebagai model lampu SSL planar yang terintegrasi dengan sumber cahaya pengeksitasi dan media pandu gelombang, sehingga dapat mentransmisikan cahaya dengan distribusi penerangan yang lebih luas di dalam ruang.

\section{BAHAN DAN METODE}

\section{Bahan}

Bahan luminesensi dibuat dari polimer hybrid organik-anorganik poli(TMSPMA) yang dimodifikasi dengan kromofor organik DCM (mengikuti prosedur penelitian yang telah dilakukan sebelumnya, yaitu sebagai bahan konversi warna emisi dengan pendekatan eksitasi langsung dan berdimensi kecil $\left(<2 \mathrm{~cm}^{2}\right)$ ) (Fitrilawati dkk 2011; Syakir dkk 2011). Polimer hybrid jenis ini telah banyak diteliti, salah satunya adalah dalam studi pembuatan grating (kisi) untuk aplikasi photopumped laser (Hidayat et al. 2012). Preparasi prekursor polimer hybrid berasal dari monomer 3-trimethoxysilylpropyl methacrylate (TMSPMA) yang dilarutkan pada etanol dan akuades dengan perbandingan $1: 4$ : 8 (monomer : etanol : akuades), selanjutnya penambahan katalis yaitu $\mathrm{HCl}$ sebesar $0,01 \%$ dari akuades yang digunakan.

Proses preparasi menggunakan metode sol-gel dan selanjutnya pembentukan ikat silang molekul anorganik pada prekursor polimer hybrid tersebut dilakukan dengan menggunakan metode fotopolimerisasi. Dalam proses fotopolimerisasi diperlukan senyawa fotoinisiator dan bantuan energi foton yang berasal dari cahaya Ultraviolet (UV). Fotoinisiator yang digunakan adalah irgacure, dengan komposisi berat sebesar $1 \%$ terhadap gel polimer hybrid.

Untuk pembuatan prekursor kopolimer hybrid organik-anorganik, digunakan kombinasi dari monomer TMSPMA dan monomer triethoxymethylsilane (TEMS) yang memiliki struktur molekul seperti diperlihatkan pada Gambar 1. 


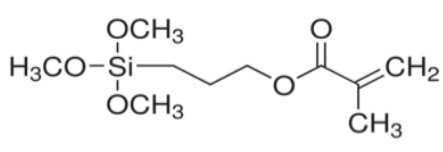

(a)

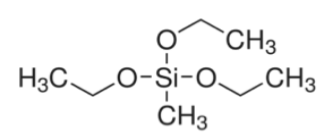

(b)

Gambar 1. Struktur monomer trimethoxysilylpropyl methacrylate (TMSPMA) (a) dan triethoxymethylsilane (TEMS) (b)

\section{Metode \\ Pembuatan Bahan Lapisan Luminesensi}

Untuk pembuatan prekursor terlebih dahulu monomer dilarutkan dengan etanol sehingga didapatkan larutan monomer yang homogen. Untuk membentuk kopolimer hybrid, kedua monomer yang telah larut dalam etanol dicampur terlebih dahulu, kemudian ditetesi dengan akuades sedikit demi sedikit sambil diaduk menggunakan pengaduk magnetik. Proses yang terakhir yaitu pemberian $\mathrm{HCl}$ sebagai katalis. Pengadukan terus dilakukan pada suhu $50{ }^{\circ} \mathrm{C}$ hingga didapatkan larutan gel bening. Kromofor organik DCM yang digunakan sebesar $0,2 \%$ dari massa prekursor. Kromofor DCM dilarutkan terlebih dahulu sebelum dicampur ke dalam prekursor polimer/kopolimer hybrid.

Berkaitan dengan kepentingan aplikasi sebagai SSL panel lebar yang terintegrasi dengan Light Guide Plate (LGP), maka dilakukan pula uji kelarutan prekursor polimer/kopolimer hybrid beserta kromofor organiknya menggunakan berbagai macam variasi pelarut. Beberapa jenis pelarut yang digunakan yaitu kloroform, isopropanol, metanol, dan etanol. Uji pelarut ini berkaitan dengan karakteristik perangkat screen printing dan media pandu gelombang.

\section{Pembuatan Lapisan Tipis Bahan Luminesensi \\ TaHAp awal pembuatan lapisan tipis} berukuran lebar menggunakan teknik yang sederhana yaitu screen printing atau solution casting. Pada teknik screen printing, digunakan perangkat yang serupa dengan cetakan sablon yaitu terdiri dari papan kayu dengan kain/jaring khusus. Beberapa taHApan persiapan pada teknik ini adalah pembuatan pola pada screen, penyiapan larutan "tinta" bahan pengkonversi warna emisi yang terbuat dari bahan prekursor polimer hybrid dan kromofor organik DCM, dilanjutkan pada proses pengeringan dan fotopolimerisasi. Karakterisasi yang dilakukan pada hasil preparasi bahan luminesensi diantaranya yaitu identifikasi spektrum FTIR pengukuran absorbansi, uji mekanik, dan pengamatan secara visual pada uji kelarutan.

\section{HASIL DAN PEMBAHASAN}

\section{Hasil Preparasi Prekursor Polimer/Kopolimer Hybrid}

Lapisan tipis polimer hybrid dibuat dengan menggunakan teknik spin coating dan tampak bening transparan. Untuk kepentingan identifikasi FTIR, lapisan tipis polimer hybrid dibuat di atas substrat silikon. Untuk mengetahui pengaruh keberadaan TEMS, maka dilakukan pengujian FTIR pada lapisan tipis poli(TMSPMA) dan poli(TMSPMA-TEMS) (kopolimer hybrid) dengan variasi komposisi antar keduanya. Hasil pengukuran dapat dilihat pada Gambar 2a, yang menunjukkan bahwa kedua polimer memiliki gugus struktur yang sama. Hal tersebut dikarenakan kedua monomer memiliki gugus yang serupa. Kedua polimer memiliki rantai utama (backbone) yang sama yaitu Si-O-Si. Perbedaan antara kedua gugus monomer penyusun polimer tersebut tersebut terletak pada gugus $\mathrm{C}=\mathrm{O}$. Pada kopolimer, kedua gugus tersebut diharapkan bergabung sehingga kehadiran gugus $\mathrm{C}=\mathrm{O}$ dan $\mathrm{C}=\mathrm{C}$ dapat diidentifikasi melalui perbedaan intensitas $\mathrm{C}=\mathrm{O}$ dan $\mathrm{C}=\mathrm{C}$ pada kopolimer poli(TMSPMA-TEMS). Perbandingan rasio antara gugus $\mathrm{C}=\mathrm{O}$ dan $\mathrm{C}=\mathrm{C}$ pada kurva FTIR menunjukkan bahwa polimer hybrid poli(TMSPMA) memiliki rasio lebih banyak dibandingkan kopolimer hybrid poli(TMSPMA-TEMS). Hasil tersebut mengindikasikan penambahan monomer TEMS pada monomer TMSPMA telah mengurangi banyaknya gugus akrilat. Spektrum UV-Vis dari film kopolimer hybrid dengan berbagai komposisi monomer dengan menggunakan pelarut kloroform diperlihatkan pada Gambar 2b. Pada film kopolimer terdapat dua puncak yaitu pada daerah sekitar $214 \mathrm{~nm}$ dan $300 \mathrm{~nm}$. Spektrum tersebut tampak berbeda dengan spektrum absorbsi film homopolimer poli(TMSPMA) yang hanya memiliki puncak pada $233 \mathrm{~nm}$. Perbandingan kurva absorbsi kopolimer dengan homopolimer mengidentifikasi puncak disekitar $300 \mathrm{~nm}$ berasal dari kopolimer. Secara spesifik dapat dikatakan puncak absorbsi pertama berasal dari molekul TMSPMA dan puncak absorbsi kedua berasal dari molekul TEMS. Pengaruh komposisi monomer pada kopolimer 
terhadap sifat mekanik diukur melalui uji kekerasan menggunakan skala Mohs. Hasil uji Mohs untuk sampel kopolimer hybrid poli(TMSPMA-TEMS) diperlihatkan pada Tabel 1. Dari data tersebut dapat diinterpretasikan bahwa semakin banyak kandungan monomer TMSPMA pada kopolimer hybrid maka ketahanan gores semakin besar, yang menunjukkan bahwa bahan semakin keras.
Sebaliknya kandungan TMSPMA yang kecil pada kopolimer menyebabkan ketahanan gores semakin kecil, yang menunjukkan bahwa sampel semakin lunak. Uji mekanik pada setiap perbandingan kopolimer hybrid menginformasikan terbentuknya kopolimer. Penambahan gugus TEMS telah berhasil mengurangi kekerasan dan kekakuan poli(TMSPMA).

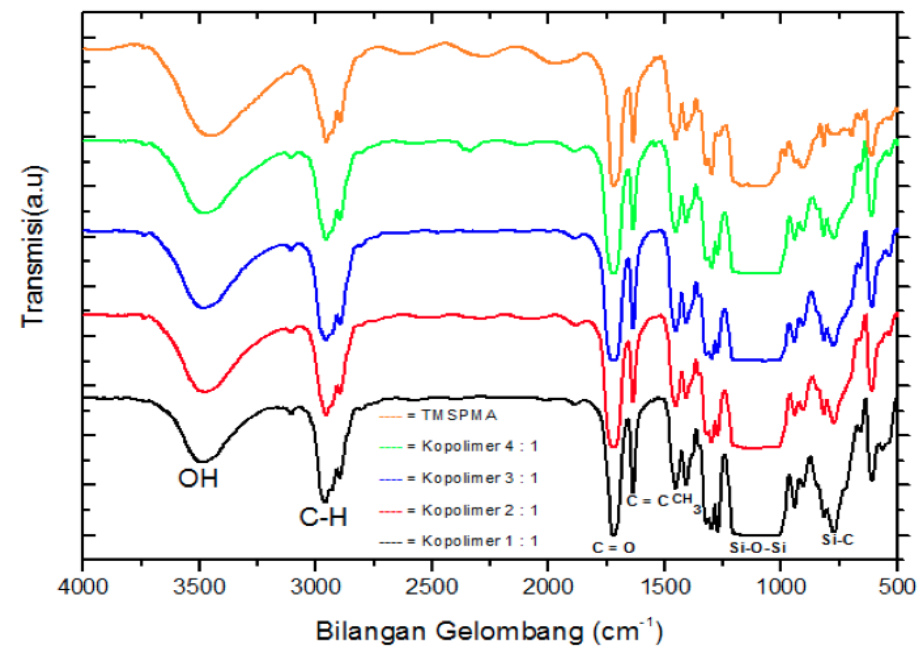

(a)

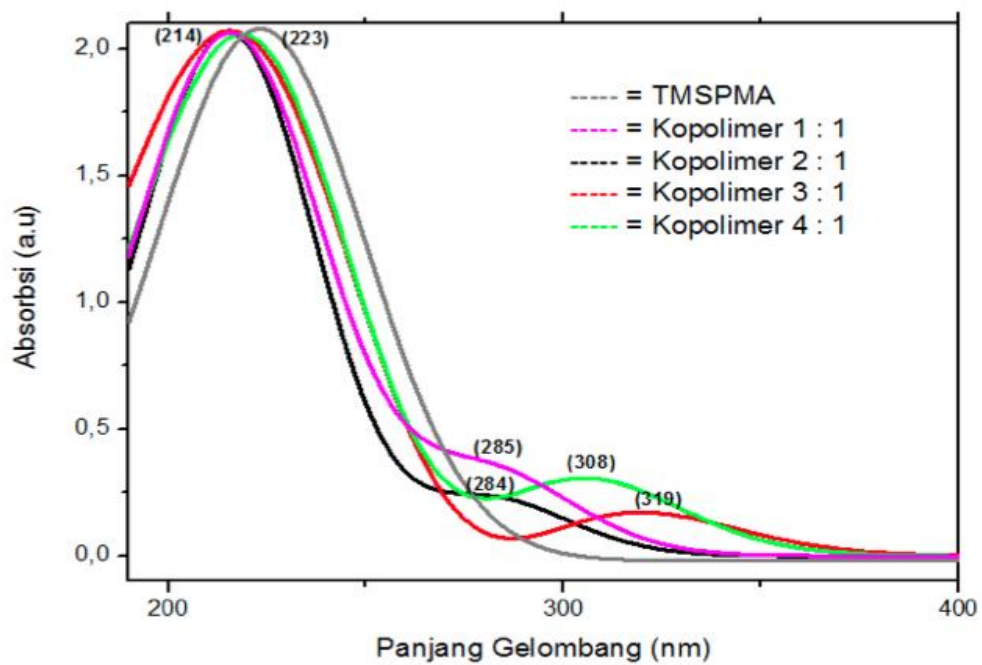

(b)

Gambar 2. (a) Spektrum FTIR kopolimer hybrid poli(TMSPMA-TEMS) dengan variasi perbandingan antar keduanya, (b) Spektrum absorbsi kopolimer hybrid.

Tabel 1. Data skala Mohs untuk masing-masing komposisi kopolimer

\begin{tabular}{ccc}
\hline Kopolimer & Skala Mohs & Keterangan \\
\hline $1: 1$ & 1 & Talc \\
$2: 1$ & 2 & Gypsum \\
$3: 1$ & 2 & Gypsum \\
$4: 1$ & 2 & Gypsum \\
TMSPMA & 3 & Calcite \\
\hline
\end{tabular}




\section{Hasil Uji Kelarutan}

Uji kelarutan prekursor poli(TMSPMA) dilakukan dengan menggunakan empat jenis pelarut yaitu kloroform yang bersifat non-polar serta pelarut metanol, etanol, dan isopropanol yang bersifat polar. Hasil uji kelarutan prekursor poli(TMSPMA) diperlihatkan pada Tabel 2, sedangkan hasil uji kelarutan inisiator diperlihatkan pada Tabel 3.

Berdasarkan hasil pengujian tersebut diketahui bahwa prekursor poli(TMSPMA) dan inisiator lebih cepat larut pada pelarut non-polar (kloroform) dan metanol, serta lebih lambat larut pada pelarut isopropanol dan etanol. Pada dasarnya secara visual, bentuk lapisan tipis poli(TMSPMA) yang dibuat dengan pelarut polar serupa dengan yang dibuat menggunakan pelarut kloroform. Untuk mengetahui keberhasilan proses sintesis polimer hybrid dilakukan indentifikasi spektrum FTIR yang diperlihatkan pada Gambar 3.

Masing-masing lapisan tipis memiliki bilangan gelombang yang identik, dengan gugus -Si-O-Si- terbentuk pada kisaran bilangan gelombang $1115 \mathrm{~cm}^{-1}$ sampai dengan $1116 \mathrm{~cm}^{-1}$, yang berasal dari rantai anorganik prekursor polimer hybrid. Keberadaan ikatan
-Si-O-Si- menandakan bahwa proses sol-gel yang dilakukan telah berhasil membuat propagasi dari bagian anorganik pada prekursor polimer hybrid. Spektrum -Si-O-Si- yang lebar menunjukkan rantai yang terbentuk cukup panjang.

Ikatan rangkap $\mathrm{C} \quad(\mathrm{C}=\mathrm{C})$ mengalami perubahan pada proses fotopolimerisasi, dimana akan terjadi setelah fotoinisiator ditambahkan ke dalam larutan prekursor polimer hybrid. Dengan bantuan cahaya, inisiator berubah menjadi radikal dan menyerang ikatan $\mathrm{C}=\mathrm{C}$ yang menyebabkan satu radikal satu ikatan rangkap $C$ terputus. Berdasarkan spektrum FTIR pada Gambar 3, terlihat bahwa intensitas $C=C$ masih cukup besar. Hal ini mengindikasikan belum terjadinya proses fotopolimerisasi pada bagian organik secara sempurna dan menyeluruh. Selain itu, jika dilakukan normalisasi spektrum terhadap puncak vibrasi $\mathrm{C}=\mathrm{O}$, secara kualitatif dapat dikatakan tidak tampak adanya korelasi antara besar polaritas pelarut terhadap transmisi. Namun khusus untuk vibrasi $\mathrm{C}=\mathrm{C}$ akan lebih besar untuk pelarut yang memiliki polaritas yang lebih besar relatif terhadap pelarut kloroform.

Tabel 2. Hasil pengujian kelarutan prekursor poli(TMSPMA)

\begin{tabular}{cccccc}
\hline Pelarut & $\begin{array}{c}\text { Massa } \\
\text { prekursor }\end{array}$ & Volume pelarut & Massa total & C (\% w/w) & Keterangan \\
\hline Kloroform & $1,5 \mathrm{gram}$ & $1,5 \mathrm{ml}$ & $3,7 \mathrm{gram}$ & $40,5 \%$ & $* * *$ \\
Isopropanol & $1,5 \mathrm{gram}$ & $1,5 \mathrm{ml}$ & $2,7 \mathrm{gram}$ & $56,2 \%$ & $* *$ \\
Etanol & $1,5 \mathrm{gram}$ & $1,5 \mathrm{ml}$ & $2,7 \mathrm{gram}$ & $56,2 \%$ & $* *$ \\
Metanol & $1,5 \mathrm{gram}$ & $1,5 \mathrm{ml}$ & $2,7 \mathrm{gram}$ & $56 \%$ & $* * *$ \\
\hline
\end{tabular}

Keterangan: pengamatan dilakukan secara visual

${ }^{* * *}$ )sangat mudah larut; **)mudah larut; *)agak sulit larut

Tabel 3. Hasil pengujian kelarutan inisiator dengan konsentrasi perbandingan massa prekursor dan volume pelarut sebesar $0,07 \mathrm{gram} / \mathrm{cm}^{3}$

\begin{tabular}{cccccc}
\hline Pelarut & $\begin{array}{c}\text { Massa } \\
\text { prekursor }\end{array}$ & Volume pelarut & Massa total & C (\% w/w) & Keterangan \\
\hline Kloroform & $1,5 \mathrm{gram}$ & $1,5 \mathrm{ml}$ & 3,7 gram & $40,5 \%$ & ${ }^{* * *}$ \\
Isopropanol & $1,5 \mathrm{gram}$ & $1,5 \mathrm{ml}$ & 2,7 gram & $56,2 \%$ & $* *$ \\
Etanol & $1,5 \mathrm{gram}$ & $1,5 \mathrm{ml}$ & 2,7 gram & $56,2 \%$ & $* *$ \\
Metanol & $1,5 \mathrm{gram}$ & $1,5 \mathrm{ml}$ & 2,7 gram & $56 \%$ & $* * *$ \\
\hline
\end{tabular}

Keterangan: pengamatan dilakukan secara visual

$\left.{ }^{* \star *}\right)$ sangat mudah larut; ${ }^{* *}$ )mudah larut; *)agak sulit larut 
Berdasarkan Tabel 4, yaitu identifikasi spektrum FTIR setelah dinormalisasi terhadap ikatan $\mathrm{C}=\mathrm{O}$, penggunaan pelarut metanol memiliki karakteristik yang mirip dengan menggunakan pelarut kloroform. Dengan demikian, pelarut metanol dapat digunakan untuk aplikasi SSL planar, mengingat kesesuaian jenis pelarut dengan perangkat preparasi dan jenis bahan LGP.

\section{Hasil Desain Awal SSL Planar}

Untuk kepentingan aplikasi, maka diperlukan desain awal model lampu SSL planar dengan pembuatan lapisan menggunakan teknik screen printing, seperti yang terlihat pada Gambar 4. Bahan luminesensi organik, salah satunya adalah DCM akan dimasukkan dalam medium pendispersi polimer hybrid dan digunakan sebagai "tinta" untuk pembuatan lapisan tipis dengan teknik screen printing.
Kemampuan pembuatan lapisan tipis bahan pengkonversi yang berukuran besar dengan teknik screen printing sangat diperlukan karena teknik ini biasa digunakan pihak industri berkaitan dengan prosesnya yang mudah dan biayanya murah. Lapisan tipis poli(TMSPMA) yang mengandung kromofor DCM (Gambar 4b) dapat mengemisikan cahaya ke seluruh permukaan relatif secara merata dan sudah dapat memperlihatkan potensi aplikasi sebagai model SSL planar. Namun lapisan tipis yang dihasilkan masih memerlukan perbaikan, salah satunya berupa homogenitas ketebalan yang masih belum sempurna. Beberapa perbaikan yang perlu dan akan dilakukan adalah penggunaan filter untuk memisahkan larutan polimer dan pengotor serta perbaikan kebersihan lingkungan untuk meminimalkan kotoran yang dapat mempengaruhi kualitas lapisan.

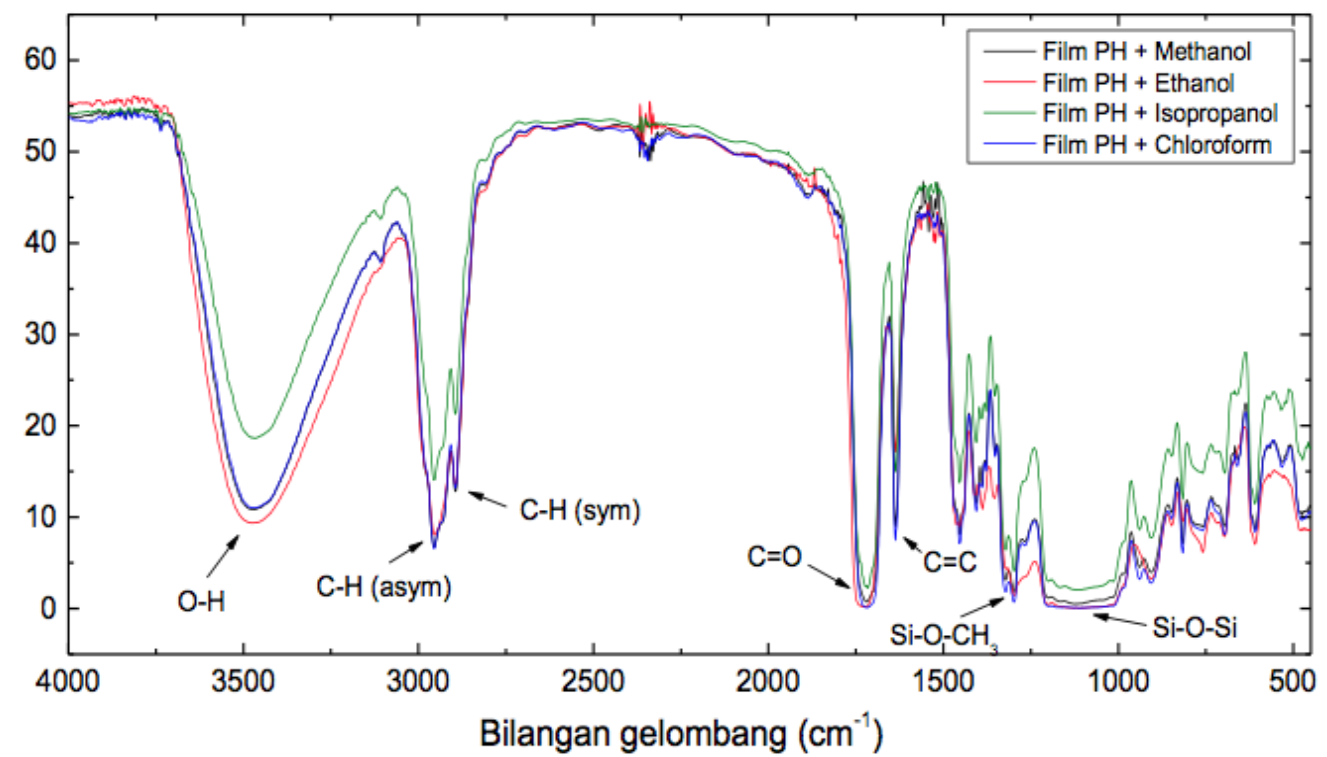

Gambar 3. Spektrum FTIR dari lapisan tipis poli(TMSPMA) dipreparasi menggunakan berbagai macam jenis pelarut

Tabel 4. Transmitansi FTIR dari lapisan tipis poli(TMSPMA) yang dibuat dengan menggunakan berbagai jenis pelarut setelah dinormalisasi pada vibrasi ikatan $\mathrm{C}=\mathrm{O}$

\begin{tabular}{ccccc}
\hline \multirow{2}{*}{ Identifikasi gugus } & \multicolumn{4}{c}{$\% \mathrm{~T}$} \\
\cline { 2 - 5 } C-H (asimetris) & Kloroform & Isopropanol & Etanol & Metanol \\
\hline $\mathrm{C}-\mathrm{H}$ (simetris) & 24,12 & 21,75 & 14,04 & 11,04 \\
$\mathrm{C}=\mathrm{O}$ & 0,20 & 34,98 & 23,82 & 22,11 \\
$\mathrm{C}=\mathrm{C}$ & 13,76 & 0,20 & 0,2 & 0,20 \\
$\mathrm{Si}-\mathrm{O}-\mathrm{CH}_{3}$ & 1,32 & 3,63 & 30,24 & 15,15 \\
$\mathrm{Si}-\mathrm{O}-\mathrm{Si}$ & 0,18 & 0 & 2,3 & 2,11 \\
\end{tabular}




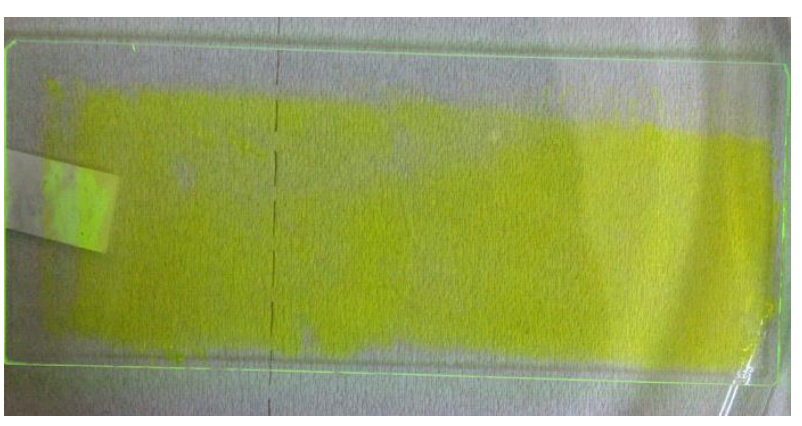

(a)

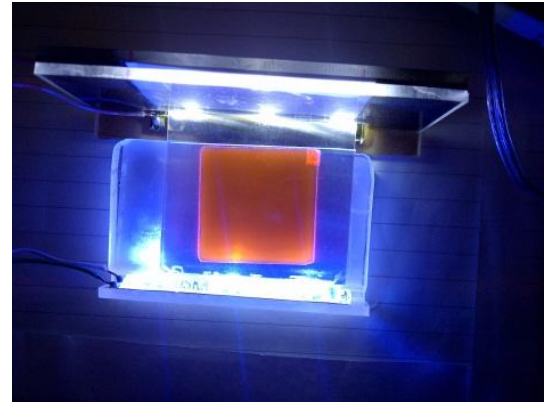

(b)

Gambar 4. (a) Lapisan tipis polimer hybrid yang dibuat dengan teknik screen printing, (b) Desain awal lampu SSL planar

\section{KESIMPULAN}

Penelitian ini telah berhasil mengembangkan bahan luminesensi yang menggunakan matriks polimer/kopolimer hybrid dan phosphor organik. Hasil kajian kelarutan polimer hybrid poli(TMSPMA) memungkinkan untuk pembuatan lapisan tipis dengan menggunakan teknik screen printing dan LGP. Hasil ini sangat penting karena sebelumnya pada pembuatan lapisan tipis bahan luminesensi tersebut selalu digunakan pelarut kloroform, padahal perangkat screen dan media pandu gelombang $L G P$ yang berbasis akrilik tidak dapat bertahan pada pelarut kloroform. Selain itu, pada studi ini telah diperlihatkan lapisan tipis yang dibuat dengan teknik tersebut dapat mengemisikan cahaya ke seluruh permukaan relatif secara merata sehingga memiliki potensi untuk pengembangan model lampu SSL planar.

\section{UCAPAN TERIMA KASIH}

Penelitian ini didanai oleh Penelitian Desentralisasi (Penelitian Unggulan Tinggi) Tahun Anggaran 2013 DIPA UNPAD nomor kontrak 023.04.2/189726/2013 tanggal 5 Desember 2012 dan Penelitian Desentralisasi (Penelitian Unggulan Tinggi) Tahun Anggaran 2014, DIPA UNPAD nomor: 023.04.2.189726/2014 tanggal 5 Desember 2013.

\section{DAFTAR PUSTAKA}

Crawford, M.H., J.J. Wierer, A.J. Fischer, G.T. Wang, D.D. Koleske, G.S. Subramania, M.E. Coltrin, and J.Y. Tsao. 2013. Solid state lighting: toward smart and ulta-efficeint materials, devices, lamps and systems. Photonics Vol. 3: Photonics
Technology and Instrumentation. America : John Wiley\&Son.

Fitrilawati, N., L. Syakir, Y. Pebriani, S. Handayani, S. Hidayat, T. Saragi, R. Siregar, P.Pitriana, dan R. Hidayat. 2011. Pengembangan phosphor organik sebagai bahan konversi warna emisi untuk aplikasi lampu SSL. Jurnal material dan energi indonesia 1 (3) : 188-195.

Held, G. 2009. Introduction to light emitting diode technology and application. Boca Raton. FL : CRC Press.

Hidayat, R., S. Hidayat, Fitrilawati, M. Herman, O. Tjia, A. Fujii, and M. Ozaki. 2012. Distributed feedback grating fabricated from hybrid polymer precursor gel by employing short-pulse laser interference for photo-pumped laser application. Polymer advanced technology 23 : 1264-1270.

Steckl, J., J. Heikenfeld, and S.C. Allen. 2005. Light wave coupled flat panel display and solid-state lighting using inorganic/organic materials. IEEE/OSA Journal of display technology 1 : 157166.

Syakir, N., Y.S. Handayani, dan Fitrilawati. 2011. Pengaruh panjang gelombang eksitasi terhadap koordinat warna emisi pada bahan konversi warna berbasis polimer hybrid. Jurnal Material dan Energi Indonesia 1 (3) : 173-179.

Travis, A., T. Large, N. Emerton, and S. Batchieche. 2009. Collimated light from a waveguide for a display backlight. Optics Express 17 (22) : 19714 19719.

Travis, A., T.A. Large, N. Emerton, and S.N. Bathiche. 2013. Wedge optics in flat panel displays. Proceedings of the IEEE 101 (1) : $45-60$. 
Tsao, Y. 2004. Solid-state lighting: lamps, chips, and materials for tomorrow. IEEE circuits \& devices $20: 28-37$.
Zukaukas, M.S. Shur, and R. Gaska. 2002. Introduction to Solid State Lighting. New York : Wiley- Interscience. 